\title{
Bacterial Cellulose for Several Medicine Areas: Future Insights
}

\author{
Pierre Basmaji1 ${ }^{1}$, Gabriel Molina De Olyveira ${ }^{1 *}$, Mohamed Kanjou², Helena Reichert ${ }^{1}$ \\ ${ }^{1}$ Innovatec's-Biotechnology Research and Development, São Carlos, Brazil \\ ${ }^{2}$ SKGH Ajm., GEM International, Dubai, United Arab Emirates \\ Email: *gabriel.ufabc@gmail.com
}

How to cite this paper: Basmaji, P., De Olyveira, G.M., Kanjou, M. and Reichert, H. (2022) Bacterial Cellulose for Several Medicine Areas: Future Insights. Journal of Biomaterials and Nanobiotechnology, 13, 1-23. https://doi.org/10.4236/jbnb.2022.131001

Received: October 8, 2021

Accepted: December 6, 2021

Published: December 9, 2021

Copyright (c) 2022 by author(s) and Scientific Research Publishing Inc. This work is licensed under the Creative Commons Attribution International License (CC BY 4.0).

http://creativecommons.org/licenses/by/4.0/

(c) (i) Open Access

\begin{abstract}
Bacterial cellulose (BC)-Nanoskin ${ }^{\circledast}$ has become established as a new biomaterial and can be used in several medicine areas, especially for medical devices mainly in dental and orthopedics applications. In addition, biomaterials have rise because of the increased interest in tissue engineering and regeneratine medicine materials for wound care and skin cancer treatment. The BC process production can be changed by different fermentation process. It has particular properties that make it an ideal candidate as a medical material: high mechanical properties, biocompatibility to the host tissue, and production in various shapes and sizes. This review describes a behavior investigation of this biomaterial in human medicine with bacterial cellulose, skin cancer, covid-19 and 3-D print for medical area.
\end{abstract}

\section{Keywords}

Bacterial Cellulose, Biomaterial, Nanotechnologies

\section{Introduction}

Nanotechnologies can be applied in several areas. The confinement of atoms at the nanoscale radically modifies the properties of materials, allowing for the restructuring or manufacture of numerous products [1] [2] [3] [4] [5].

In the area of health, nanotechnologies have as their main objective the construction of systems identical to those created by nature. Biomaterials, composed of molecular structures at the nanoscale, have the ability to interact with biological systems, performing the same functions as natural mechanisms. Thus, these materials can be used in the conformation of various biomedical components, such as blood vessels, skin and artificial organs, intelligent dressings, vision and hearing devices and drug delivery systems that can be implanted under the skin 
[1] [2] [3] [4] [5].

The specificity of the different types of wounds and the constant search for the most suitable treatments for each of them means that, naturally, a wide range of procedures capable of effectively treating these same wounds is currently consolidated. A procedure can be measured based on a relatively small number of parameters: wound healing speed, long-term functionality of the affected tissues and esthetic aspect. Therefore, the constant search for new methods of treating wounds should fundamentally be guided by the optimization of these aspects [5]-[10].

Among the various technologies that emerge and establish themselves as the basis for the creation and development of new products and solutions, nanotechnology will undoubtedly be one of those that will present the greatest potential for growth. Generically defined as the engineering of functional systems at a molecular scale, nanotechnology is based on the ability to manipulate and process individual atoms and molecules, something that promises to revolutionize in the short/medium term areas as diverse as the aerospace industry, tissue engineering, the food industry and medicine, among many others [5]-[10].

The concept of nanomedicine arises, of course, from the application of nanotechnology to the field of medicine. In the midst of an exponential growth phase in several ways, nanomedicine will have in the targeted drug delivery mechanisms one of its main standard bearers, which allow the administration of drugs to the body with a precision at the cellular scale and thus increase its bioavailability [10] [11] [12].

\section{What is nano?}

"Nano" is a prefix that comes from ancient Greek and means "dwarf".

1 nanometer $(\mathrm{nm})=1$ billionth of a meter, $10^{-9} \mathrm{~m}$.

Purpose of Nanotechnology:

- Create, characterize, produce and apply structures, devices and systems, controlling form and size on the nanometer scale;

- Provide conditions for the growing capacity of modern technology to see and manipulate atoms and molecules.

\section{But why!}

- Scientific curiosity;

- Expected benefits in:

Development of new drugs.

- Bionanotechnology refers to molecular-scale properties and applications of biological nanostructures.

- Tissue engineering-Molecular engines;

- Biomolecules for sensors-Drug delivery;

- Discovery of new drugs.

- Current and future applications

- Drug delivery;

- New drugs;

- Cancer treatment; 
- Implants and prostheses.

- Classic Wound healing [12] [13] [14] [15]

Classification of Dressings;

What's on the market today; Classic dressings, such as:

- Liabilities-gas;

- Interactive-hydrocolloids, Hydrogel;

- Bioactives-Activated Carbon, Calcium Alginate, Collagenase, Papain [12] [13] [14] [15].

\begin{tabular}{|c|c|c|}
\hline Names & Indications & Observation \\
\hline SODIUM ALGINATE & $\begin{array}{l}\text { Indicated in infected } \\
\text { or uninfected lesions, } \\
\text { with medium or high } \\
\text { exudation, with } \\
\text { bleeding or in the } \\
\text { presence of necrosis } \\
\text { and fibrin. }\end{array}$ & $\begin{array}{l}\text { Used as a primary dressing, } \\
\text { as it is applied over the } \\
\text { wound bed, requiring a } \\
\text { secondary dressing to } \\
\text { occlude or fix it. The } \\
\text { exchange frequency must } \\
\text { be evaluated according to } \\
\text { the amount of exudates } \\
\text { present in the wound, which } \\
\text { may remain for up to } 4 \text { days. }\end{array}$ \\
\hline HYDROCOLLOIDS & $\begin{array}{l}\text { Indicated in } \\
\text { non-infected } \\
\text { wounds, with medium } \\
\text { and low volumes of } \\
\text { exudate. Can be used } \\
\text { in the presence of } \\
\text { necrotic tissue and fibrin. }\end{array}$ & $\begin{array}{l}\text { Changing the dressing must } \\
\text { be performed whenever the } \\
\text { gel leaks. It can stay for up to } \\
7 \text { days. The gel formed with } \\
\text { wound exudate has a } \\
\text { yellowish color and an } \\
\text { unpleasant odor that } \\
\text { disappears after cleaning } \\
\text { the wound. }\end{array}$ \\
\hline $\begin{array}{l}\text { HYDROCOLLOIDS } \\
\text { IN GRANULES }\end{array}$ & $\begin{array}{l}\text { Indicated for deep and } \\
\text { highly exudative } \\
\text { wounds. They are } \\
\text { associated with the use } \\
\text { of the boards. }\end{array}$ & $\begin{array}{l}\text { The granules fill the dead } \\
\text { space in the wound bed, } \\
\text { increase the absorption of } \\
\text { exudate, extending the } \\
\text { permanence time of the plaques. }\end{array}$ \\
\hline $\begin{array}{l}\text { PAPAÍN } \\
(1 \%, 5 \% \text { OR } 10 \%)\end{array}$ & $\begin{array}{l}\text { Indicated for necrotic } \\
\text { wounds and in the } \\
\text { presence of fibrin, } \\
\text { being contraindicated in } \\
\text { cases of ischemic injury. }\end{array}$ & $\begin{array}{l}\text { It should not be used or } \\
\text { mixed with substances } \\
\text { derived or composed of } \\
\text { iron or iodine, as it is } \\
\text { easily oxidized. }\end{array}$ \\
\hline $\begin{array}{l}\text { COLLAGENASE-10\% } \\
\text { Without } \\
\text { CLORANFENICOL }\end{array}$ & $\begin{array}{l}\text { Indicated in ischemic } \\
\text { lesions and necrotic } \\
\text { wounds. }\end{array}$ & $\begin{array}{l}\text { It is indicated for wound } \\
\text { debridement, digesting and } \\
\text { removing necrotic tissue. }\end{array}$ \\
\hline $\begin{array}{l}\text { ACTIVATED COAL } \\
\text { WITH SILVER }\end{array}$ & $\begin{array}{l}\text { Indicated for infected } \\
\text { lesions, with medium } \\
\text { and high exudation, } \\
\text { with or without odor. }\end{array}$ & $\begin{array}{l}\text { Primary dressing, always } \\
\text { requiring coverage with a } \\
\text { secondary. It must be changed } \\
\text { whenever it is saturated, and } \\
\text { may remain for up to } 7 \text { days. }\end{array}$ \\
\hline
\end{tabular}


TRANSPARENT FILM DRESSINGS

POLYURETHANE FOAM

SUGAR

MEDIUM CHAIN

TRIGLYCERIDES

AND ESSENTIAL

FATTY ACIDS
Indicated for insertion sites of peripheral catheters, tunneled or untuned central catheters, intracranial pressure catheters, umbilical catheters and for protecting areas of bony prominences in patients at high risk for developing pressure ulcers.

It is indicated for wounds with deep tissue loss, partial or total, and in the cavity it is used as a filling. In wounds with superficial tissue loss or where there is a predominance of necrotic tissue, it is contraindicated.

infected wounds

Indicated for the treatment of wounds, infected or not, previously debrided, medium or little exudative. The wound must be irrigated with the solution and covered with an occlusive dressing.
In catheters, it must be changed every 72 hours; in the pressure areas. can stay for 7 days.

The frequency of changing this dressing depends on the volume of exudate drained, and it can remain in the wound bed for up to 5 days. In the presentation of wrapping, it is necessary to use secondary coverage, such as sterile double gauze or polyurethane film.

As it is an easy-access and low-cost product, it is widely used. It has numerous inconveniences such as: need for frequent changes every 2 or 4 hours, intense pain due to acidification of the environment.

Changes must be daily.

\section{Bionanotechnology-Based Dressings: Nanoskin ${ }^{\circledR}$}

\section{- Nanoskin}

Nanoskin ${ }^{\otimes}$ is a new Biotechnology indicated for the treatment of lesions, diabetic foot ulcers, and complex chronic lesions.

Purpose: applications as a drug delivery platform.

Nanoskin ${ }^{\circledast}$ meets an urgent medical demand for the treatment (and prevention) of complex chronic injuries [16]-[27]. 
Nanoskin ${ }^{\circledast}$ main Objectives are:

- Improve the patient's quality of life

- Accelerate healing of chronic injuries

- Reduce health care costs [16]-[27]

What is Nanoskin ${ }^{\circledast}$

Nanokin is a patented, $100 \%$ natural biological film, the result of many years of research in bionanotechnology. Nanoskin ${ }^{\circledast}$ is a nano-sized fiber platform with physical and mechanical properties that dramatically accelerate wound healing [16]-[27] (Figure 1).

\section{How does Nanoskin ${ }^{\bullet}$ work?}

The Nanoskin ${ }^{\circledast}$ membrane works by promoting:

- Isolation of exposed nerve endings, resulting in immediate pain relief.

- Direct contact of the membrane with the lesion layer promotes the development of new skin.

- Maintenance of the open area of the moist lesion during the regenerative process, allowing an efficient exchange of oxygen/nitrogen within their area, thus preventing infection by pathogens [16]-[27].

Nanoskin ${ }^{\circledast}$-Main features

$100 \%$ natural;

Biocompatible and non-allergenic;

No adverse reactions;

No pain sensation;

Perfect occlusion of the injured area;

Not permeable to external liquids and contaminants;

Natural antibacterial barrier and lesion nutrition;

Rapid reduction of the area of lesions by 95\% [16]-[27].

Advantages of using Nanoskin*:

- Ease of application and adaptation to the lesion layer;

- Protection and acceleration of the healing process;

- Absence of adverse reactions;

- Decrease in pain;

- Comfort for the patient;

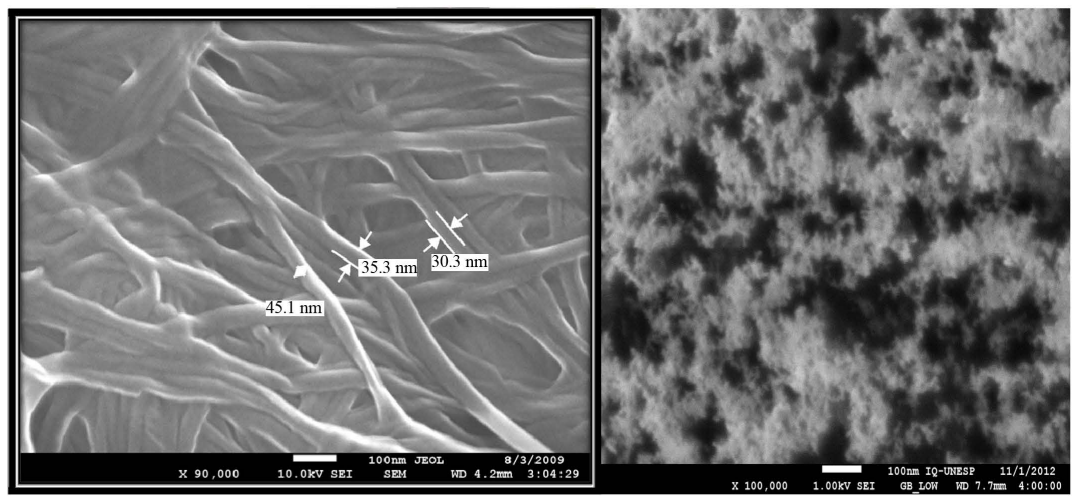

Figure 1. Formation of extracellular matrix of Nanoskin ${ }^{\circledR}$ fibers $(2 \mathrm{~nm}-40 \mathrm{~nm})$ seen by scanning microscopy. 
- Ease of drainage of secretions;

- Visualization and evolutionary control of the lesion;

- Maintenance of physiological moisture between the wound layer and the membrane;

- Occurrence of gas exchanges;

- Lower treatment cost.

Indication of use

- Dermis/skin burns;

- Dermo-abrasions;

- Excoriations;

- Skin graft donor and recipient areas;

- Nail beds (after nail exeresis);

- Diabetic ulcers;

- Venous ulcers;

- Arterial ulcers;

- Pressure ulcers;

- Evil piercing plantar;

- Infected surgical wounds;

- Decubitus bedsores;

- Physical postcauterization (cryotherapy, term cauterization, with a source of light;

- Bullousepidermolysis.

WHY Nanoskin ${ }^{\bullet}$ is different?

1) Nanoskin ${ }^{\circledR}$ made from a nano biotechnological biomimetic process.

2) Nanoskin ${ }^{\circledR}$ i s a highly hydrated film made from a random array of tape-shaped fibers between $2-40 \mathrm{~nm}$ in width.

3) The nanobioprocess produces lactic acid, which is a potent detoxifying substance, in addition to glucuronic acid (glucuronic, lactic, unique, enzymes, vitamin B1, B2, B3, B6 and B12, vitamin C, D, and K, biotin and folic acid).

4) Nanoskin ${ }^{\otimes}$ is a polysaccharide natural fibers composed of hemicellulose proteins.

5) Nanoskin ${ }^{\circledast}$ increases the activity of NK cells (Natural Killer cells), T cells (T cells are a type of lymphocyte-white blood cells) and cells (B cell is a kind of lymphocyte that constitutes the immune system).

6) This polyunsaturated fatty acids and fatty acids derived from Nanoskin ${ }^{\circledast}$, which activate Peroxisome Proliferator Activated Receptors (PPARs), this receptor increases in keratinocytes after skin damage and becomes important regulators of reepithelialization.

7) Variety of factors, because Nanoskin ${ }^{\circledast}$ can activate the intracellular signaling pathways that regulate the various stages of the wound, re-epithelialization and granulation.

The advantages of Nanoskin ${ }^{\circledast}$ nano dressings, it works on all types of wounds, this represents economy and comfort for healthcare professionals as well as for the patient. See the Figure below; [16]-[27]. 


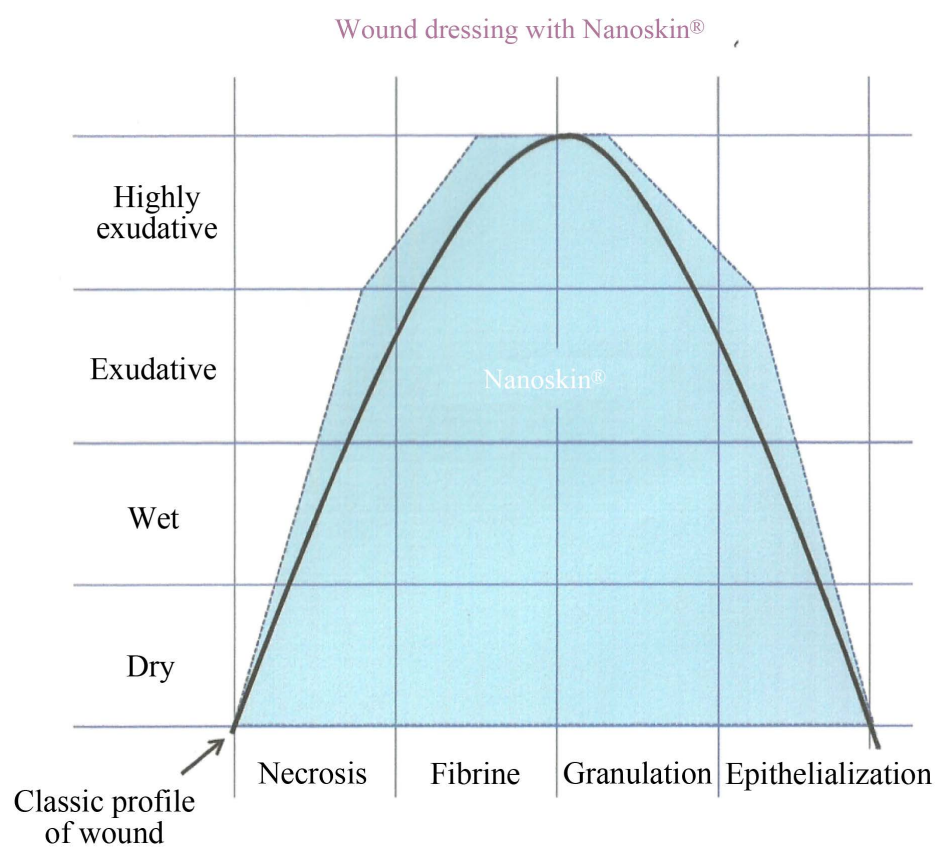

\section{COMMON QUESTIONS}

What is the Nanoskin ${ }^{\oplus}$ membrane made of?

The Nanoskin membrane is made from tea stem cells with nano-structures identifies the human skin.

This membrane is $100 \%$ natural obtained through biotechnological process.

\section{HOW DOES NANOSKIN ${ }^{\bullet}$ WORK?}

Nanoskin ${ }^{\oplus}$ acts as a temporary skin replacement, providing ideal and necessary conditions for a faster, high-quality healing process.

Nanoskin ${ }^{\oplus}$ works as a protective barrier against microorganisms,

The Nanoskin ${ }^{\circledast}$ membrane works by promoting:

- Isolation of exposed nerve endings, resulting in immediate pain relief.

- Direct contact of the membrane with the lesion layer promotes the development of new skin.

- Maintenance of the raw area of the lesion moist during the regenerative process, allowing an efficient exchange of oxygen/nitrogen within their area, thus preventing infection by pathogens.

\section{WHY DOES NANOSKIN` RELIEVE PAIN QUICKLY?}

The perfect adhesion of the film to the injured area isolates the nerve endings with immediate pain relief.

\section{Why choose Nanoskin ${ }^{\bullet}$ membrane? WHY is Nanoskin different?}

1) Nanoskin ${ }^{\oplus}$ made from nano-biotechnological biomimetic scaffolding process.

2) Nanoskin is a highly hydrated film composed of a random array of fibers in the form of a $2 \mathrm{~nm}$ wide ribbon.

3) This nanobio process produces vitamin complex and potent detoxifying substances. 
4) Nanoskin ${ }^{\circledast}$ is a natural fiber based on polysaccharides composed of hemicellulose proteins.

5) Increase the activity of NK cells (Natural Killer Cell), T cells ( $\mathrm{T}$ cells are a kind of lymphocytes - white blood cells) and cells (B cell is a kind of lymphocytes that make up the immune system).

6) These polyunsaturated fatty acids present in Nanoskin ${ }^{\circledast}$, which activate peroxisome proliferator-activated receptors (PPARs); these receptors are increased in keratinocytes after skin injury and are considered important regulators of reepithelialization.

7) Nanoskin ${ }^{\circledast}$ can activate intracellular signaling pathways that regulate the various stages of the wound: reepithelialization and granulation [16]-[27].

\section{Wound Healing Process: Important Factors}

Cells:

- Inflammatory cells (neutrophils, lymphocytes, macrophages...) "cleaning" the wound and providing growth factors

- Skin cells: produce: collagen, reticulin, elastin fibers from the extracellular matrix

- Endothelial cells that regenerate blood vessels (angiogenesis) [28]-[38]

\section{Molecules: Growth factors and Citocines}

- Plates that form the clot and provide the growth factors, mediators of intercellular communication [28]-[38].

\begin{tabular}{|c|c|c|c|}
\hline & Function & $\begin{array}{l}\text { Acute } \\
\text { Wound }\end{array}$ & $\begin{array}{l}\text { Chronic } \\
\text { Wound }\end{array}$ \\
\hline $\begin{array}{c}\text { EGF } \\
(\mathrm{PI}, \mathrm{Ma}, \mathrm{F})\end{array}$ & epithelialization & $\uparrow$ & $\downarrow$ \\
\hline $\begin{array}{c}\text { FGF-2 } \\
(\mathrm{K}, \text { MAS. F. CE, CML. C) }\end{array}$ & $\begin{array}{c}\text { Granulation, epithelialization, } \\
\text { extracellular matrix }\end{array}$ & $\uparrow$ & $\downarrow$ \\
\hline $\begin{array}{c}\text { TGF- } \beta \\
(\mathrm{PI}, \mathrm{K}, \mathrm{M}, \mathrm{L}, \mathrm{F})\end{array}$ & & $\uparrow$ & $\downarrow$ \\
\hline $\begin{array}{c}\text { PDGF } \\
(\mathrm{PI}, \mathrm{K}<\mathrm{Ma}, \mathrm{CE}, \mathrm{F})\end{array}$ & & $\uparrow$ & $\downarrow$ \\
\hline VEGF & Granulation & $\uparrow$ & $\downarrow$ \\
\hline $\begin{array}{c}\text { IL-1 (N, M, Ma, K) } \\
\text { IL-6 (N, Ma) } \\
\text { TNF- } \boldsymbol{\alpha}(\mathrm{N}, \mathrm{Ma})\end{array}$ & $\begin{array}{l}\text { inflammation, } \\
\text { epithelialization }\end{array}$ & $\uparrow$ & $\uparrow$ \\
\hline
\end{tabular}

Metalloproteinases (MMPs) are a family of enzymes that when activated, they degrade extracellular matrix components (ECM) (collagen...) and growth factors. Collectively, these enzymes are capable of degrading all kinds of extracellular matrix proteins, but also can process a number of bioactive molecules. They are known to be involved in the cleavage of cell surface receptors, the release of apoptotic ligands (such as the FAS ligand), and chemokine/cytokine inactiva- 
tion.

MMPs are also thought to play a major role in cell behaviors such as cell proliferation, migration (adhesion/dispersion), differentiation, angiogenesis, apoptosis and host defense [38]-[43].

\section{Inflammatory mediators}

Prostaglandins, leukotrienes, interleukin-1, Nitric oxide, anti-microbial peptides, Pro-inflammatory and antagonist cytokines.

Clotting protein

All these molecules are influenced by physicochemical conditions, temperature, humidity, $\mathrm{pH}, \mathrm{pO}_{2}, \mathrm{pCO}_{2}$, so Its operation is facilitated by the hot and humid environment of the fibrin clot.

\section{Extracellular matrix}

Three-dimensional structure, it is constantly renewed, whose structure is composed of:

- Collagen, elastin, reticulin produced by fibroblasts...

Fundamental substance: Proteoglycans, glycosaminoglycans, hyaluranic acid, guide cell migration [43]-[48].

\section{Definitions and Classification of Wounds}

A wound is a skin lesion represented by a disruption of tissue continuity and a disruption of the skin barrier that requires a complex dynamic process to repair or heal. It can be superficial, involving only the epidermis (erosion), part of the dermis or being deep with exposure of the subcutaneous tissue. Its evolution depends on its extension and depth, but also on local or general factors that can delay or prevent its healing [48]-[53].

The acute wound results from a surgical or traumatic injury and progresses through the healing phases in approximately one month.

Chronic wound a wound that has lasted longer than 4 - 6 weeks. The chronic wound does not go through the stages of healing stages in sequence or over time. Underlying diseases (diabetes, venous/arterial insufficiency) or (diabetes, venous/arterial insufficiency) or external factors contribute to the failure of the healing process. The potential for wound healing will depend on the local conditions and the general condition of the patient. The presence of certain local or general factors can be an indicator of risky wounds with little chance of spontaneous healing [48]-[53].

TYPES OF WOUNDS

SURGICAL WOUND:

Intentionally created skin incision.

ATONIC WOUND

Non-progressive wound, usually dry, usually covered with whitish tissue.

CONTAMINATED WOUND

Microbial presence in the wound, commensal flora

COLONIZED WOUND 
Bacterial proliferation in the wound without any systemic immune response.

INFECTED WOUND

Invasion and multiplication of microorganisms causing a local and/or systemic inflammatory response and clinical symptoms and signs of infection (fever, heat, redness, pain, edema).

UNDERMINE WOUND

It contains more or less sinuous and deep cracks under the wound margins.

CAVITY WOUND

Contains a hollow part

FISTULOUS INJURY

It involves communication between a hollow organ and the skin.

Blister

Formed by a displacement between the epidermis and the dermis, full of serosity: the blister is characteristic of second-degree burns.

GENERAL FACTORS THAT Hinder the HEALING PROCESS

Intrinsic factors:

- Age;

- Severely malnourished patient;

- Concomitant disease (chronic diseases involving the cardiorespiratory system, diabetes, renal insufficiency...);

- Insufficient tissue oxygenation;

- Immunodeficiency.

Pathology affecting tissue vascularization and its oxygenation:

- Arteriosclerosis;

- Arthritis and small vessel diseases;

- Venous insufficiency;

- Chronic lung failure;

- Lymphatic insufficiency.

Extrinsic factors

- Medication;

- Immunosuppressive treatments;

- Corticosteroid therapy;

- Radio + chemotherapy;

- Infection;

- Stress.

\section{Iatrogenic factors}

- Inadequate wound care;

- Local ischemia;

- Wound dehydration.

\section{HEALING PROCESS}

Healing is a complex and dynamic biological process that leads to wound repair. The duration of healing varies depending on the intensity, contusion or superinfection [48]-[53].

Healing is a complex and dynamic biological process that leads to wound re- 
pair. The duration of healing varies depending on the intensity, contusion or superinfection [48]-[53].

The treatment and care of a wound is difficult to delineate. Even in the presence of identical etiological lesions, the course of the healing process can take place in a totally different way depending on the type of wound, the location or the person [48]-[53].

\section{Normal wound healing follows a four-step process}

Phase 1: Inflammatory (detersive-inflammatory): After vasodilation with bleeding, there is constriction of the ruptured vascular ends, with coagulation and production of an exudate rich in cells (granulocytes, macrophages, monocytes) that will eliminate (detersion phase), lymphatic and/or by the formation of pus, bacteria, dead tissue and foreign microparticles.

At this stage, the wound shows all the characteristic signs of inflammation: redness, swelling, heat, pain.

The dilation of blood capillaries is responsible for redness and heat. The increase in its permeability, by promoting plasma exudation, is responsible for swelling, heat and pain due to pressure on sensitive nerve endings.

This reactive phase usually lasts between 3 and 6 days. [48]-[53]

Phase 2: Granulation or proliferative: This phase corresponds to fibroblast proliferation, angiogenesis and extracellular matrix synthesis.

Immediately after the inflammatory phase, a granulation tissue with capillary neoformation (neovascularization or angiogenesis) begins to organize itself within a network of collagen and elastin (produced by fibroblasts) that will bring in situ oxygen, nutrients and cells necessary for tissue repair.

- Macrophages at this stage still play an essential role in the production of growth factors or cytokines capable of promoting fibroblast proliferation and collagen synthesis. At this stage, the scar is a young fibrosis containing many fibroblasts and a loose fibrillar web on the periphery of the loss of substance.

- The edge of a wound is composed of fibroblasts, an inflammatory infiltrate (monocytes, lymphocytes, polynuclear cells), surface fibrin and new vessels in an swollen fibrillar web.

The contraction of the wound to bring it closer to the edges is closely related to the formation of granulation tissue and the transformation of certain fibroblasts into myofibroblasts capable of contracting and transmitting their contractile activity to the surrounding tissue through the interaction between cytoskeleton and extracellular matrix proteins.

This phase, which is very active from the 7th day onwards, can last up to 3 weeks [48]-[53].

Stage 3: Epithelialization: After tissue repair, the wound retracts and gradually becomes covered by new epithelium $=$ epithelialization process.

Epidermal cells capable of dividing (base layer cells = keratinocytes) multiply and begin to cover the granulation tissue from the edges of the wound. To be able to migrate properly, these keratinocytes need healthy, moist and level granulation tissue. As a result of the formation of this first cell layer, the epithelium 
thickens by cell division and soon becomes more resistant. the wound is closed [48]-[53].

Phase 4: Maturation: This phase called "maturation" starts in the first few days in the case of a sutured wound, but can also last for months in the case of extensive and very open wounds. It is characterized by connective tissue remodeling and scar formation.

The granulation tissue disappears to give way to fibrous connective tissue. Collagen fibers thicken which increases resistance to tensile forces. The number of capillaries decreases, as does the blood flow.

Excess water and blood vessels disappear and the scar becomes firmer.

However, in all cases the scars are less resistant and less elastic than normal skin, in part due to a certain deficit of elastin.

This phase can last for several months [48]-[53].

International Visual Wound Color Scale

The international visual wound color scale describes the different stages of wound healing and allows to use a common language.

BLACK-Necrotic tissue: wound covered by a black plaque, dry or wet.

YELLOW-Fibrinous tissue: wound covered by yellowish or whitish tissue, more or less adherent.

RED-Granulation tissue: red, vascularized wound, with islets of buds.

PINK-Epithelialization tissue: wound covered by a thin epithelium. Is it pink, pearlescent or shiny.

GREEN-infected wound [48]-[53].

\section{Nanoskin ${ }^{\circledR}$ Wound Treatment}

In this chapter we will present:

1) Wounds in pressure ulcers and covid 19;

2) Tumor wounds;

3) Wounds in general;

Pressure sores.

A pressure ulcer is a localized lesion of the skin and/or underlying tissue, usually at the level of a bony prominence, due to pressure or pressure associated with shear or friction. Several contributing factors are associated with pressure ulcers; however, the importance of these factors remains to be determined. Pressure ulcers severely affect patients, interfering with their functional recovery, often causing pain and promoting the development of serious infections. Pressure ulcers are classified into four stages: [48]-[53].

\begin{tabular}{cl}
\hline Stage I & Skin color is slightly altered, but there are no open wounds. \\
Stage II & The skin splits, forming an ulcer. \\
Stage III & The lesion has worsened and forms a crater in the tissue. \\
Stage IV & $\begin{array}{l}\text { The wound is very deep and causes significant tissue destruction; } \\
\text { the wound can damage muscles, bones and tendons. }\end{array}$
\end{tabular}




\section{RISK FACTORS}

For some categories of patients, the assessment requires the physician to consider certain factors that may increase the risk of skin damage or compromise healing. Advanced age, declining general nutritional and mental health, loss of mobility, deficits in sensory perception, incontinence and changes in skin characteristics were recognized as early signs of pressure-associated injuries. The risk is increased in people with high blood pressure, contractures or a history of stroke. The incidence and prevalence rates of pressure ulcers remain higher in intensive care due to the large number of critically ill patients. It can be difficult to assess skin condition and visualize bony prominences in very obese people. Surgical patients are particularly susceptible to the development of pressure ulcers due to their prolonged intraoperative and immediate postoperative immobility. In many terminal patients, multiple factors and comorbidities increase the risk of developing pressure ulcers and need to be identified [48]-[53].

Cases:

Pressure ulcer after covid 19;

Patient was incubated because of covid 19 developed pressure ulcer;


Work of nurse Helena Reichert

Other cases: under treatment.

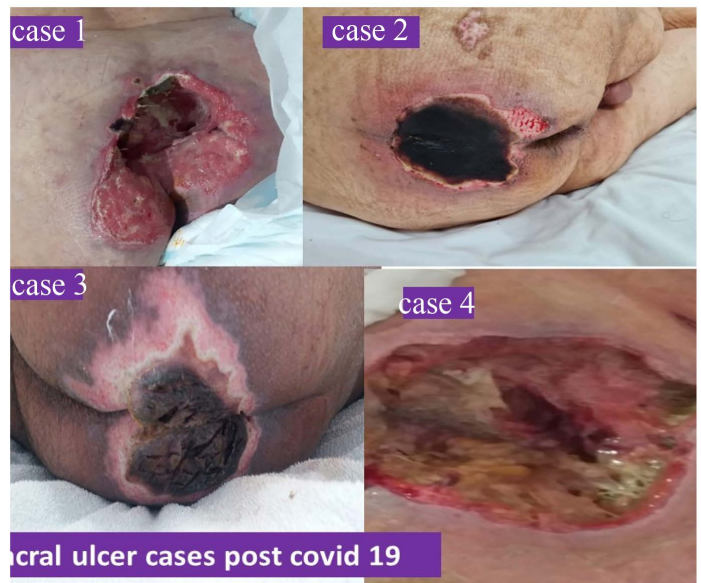




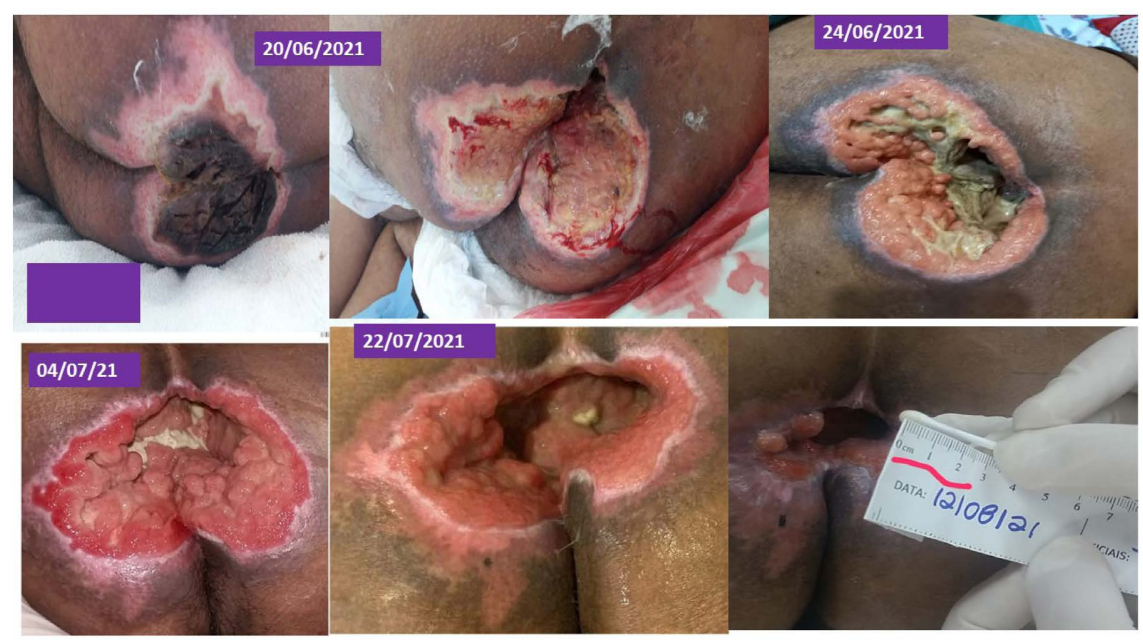

A 43-year-old man was admitted at the worst time of the pandemic in Araraquara, in early May, and spent 43 days in hospital, most of them intubated.

Clinical cases with carcinoma treated with Nanoskin ${ }^{\bullet}$
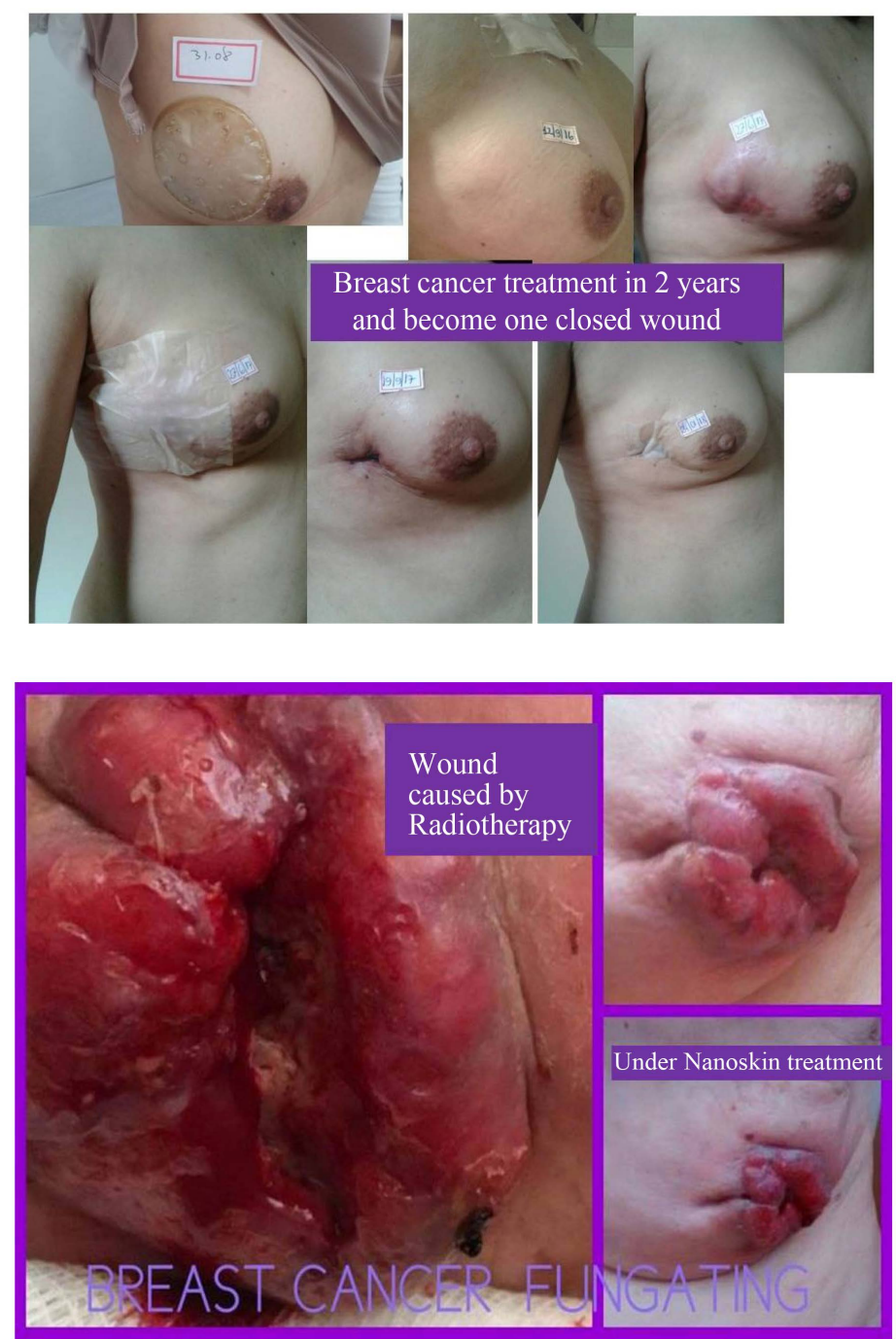

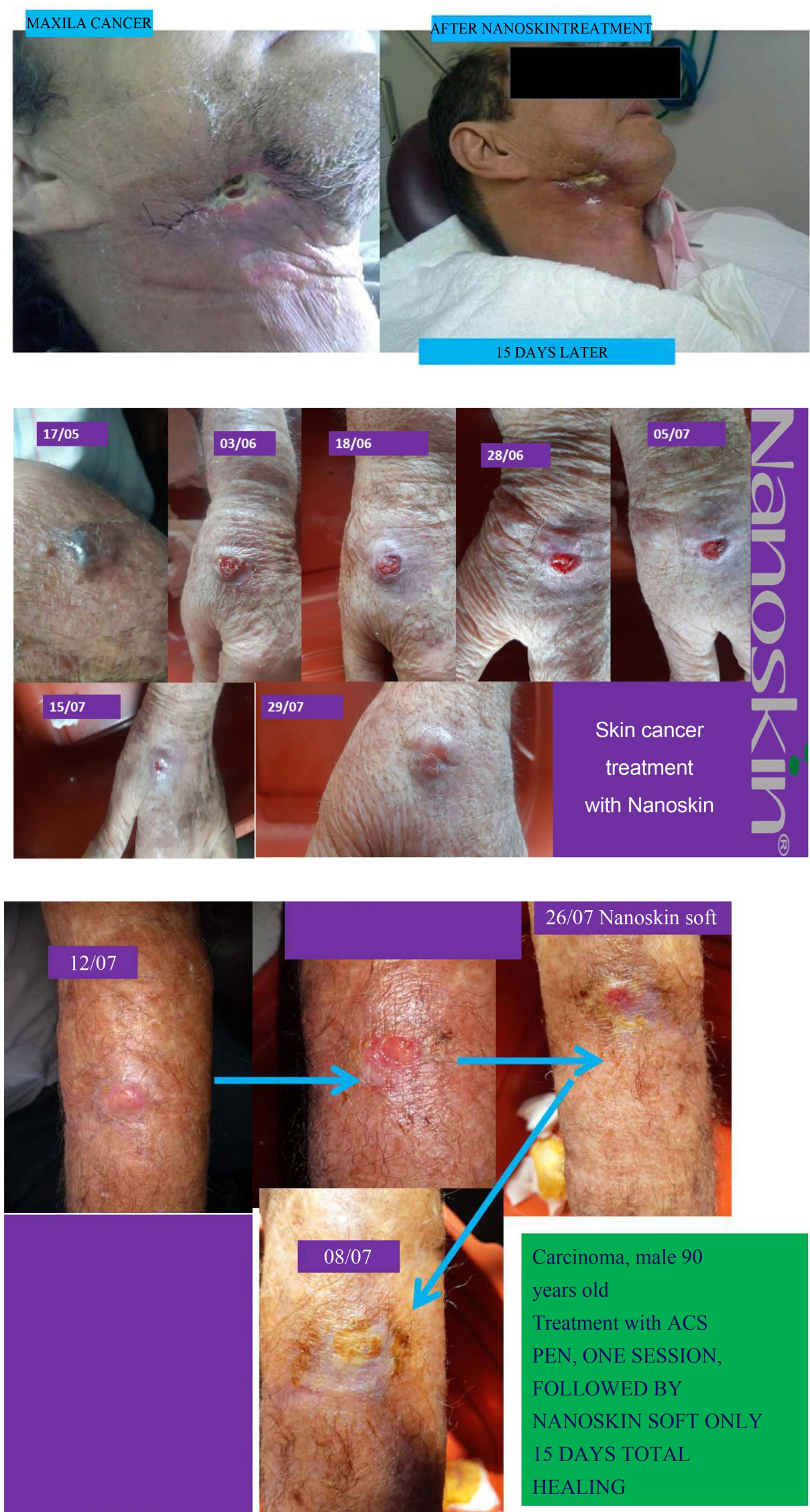

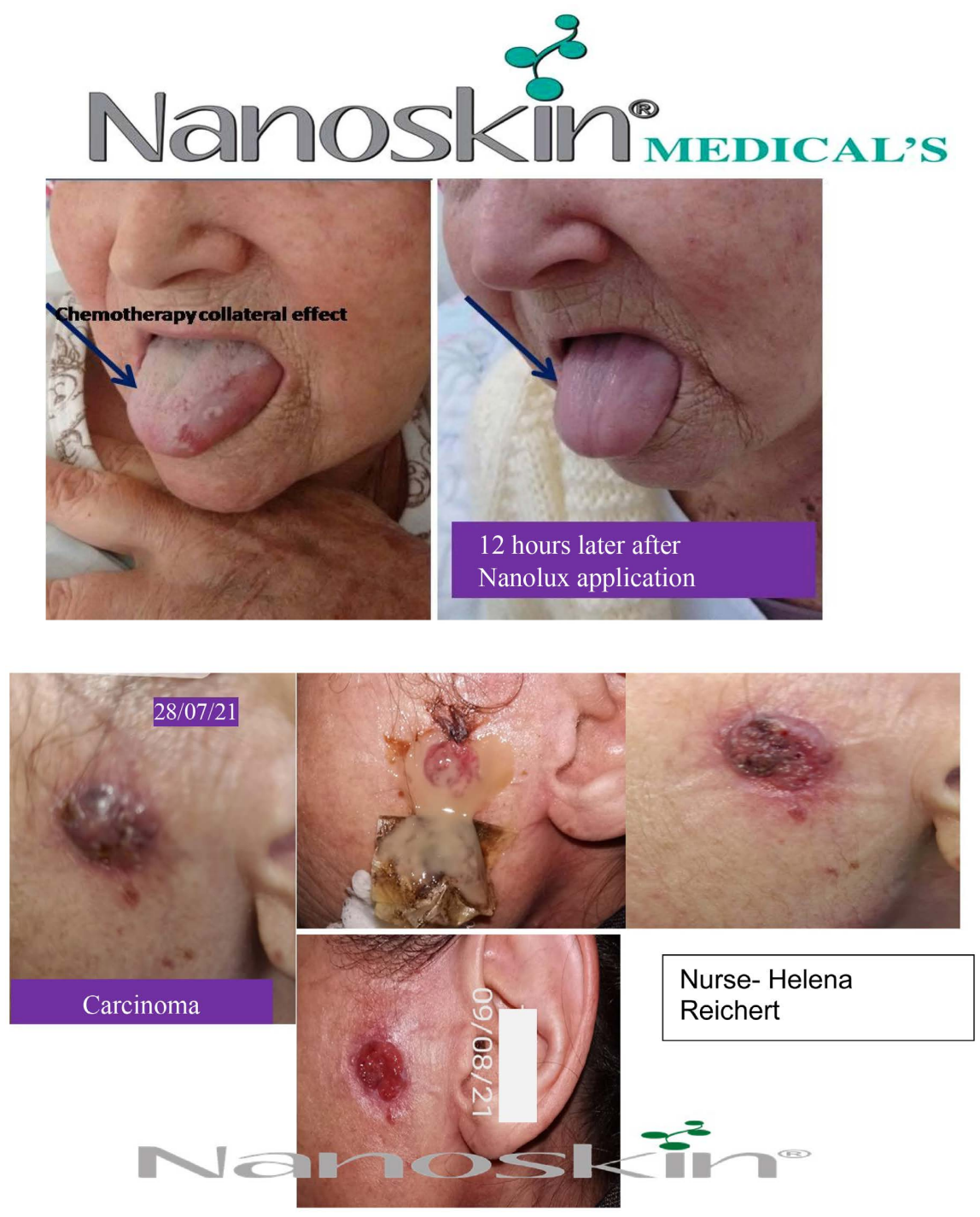

\section{3D Print Applications with Nanoskin ${ }^{\circledR}$}

Just over twenty years ago, we've witnessed the advent of additive manufacturing or $3 \mathrm{D}$ printing of biomaterials. This is done by stacking successive layers on a support, as with ink on a sheet.

3D printing makes it possible to produce in series at a lower cost, but also to manufacture customized parts that adapt to the patient's anatomy from 3D files obtained from medical images.

In 2011, a 3D printed titanium jaw bone was implanted for the first time. Two years later, a 22 -year-old woman received a 3D-printed skull prosthesis in the Netherlands.

In France, 3D printing is now required by many hospitals to manufacture custom knee or hip prostheses. It is also used to prepare complex interventions (mainly in maxillofacial surgery), by performing a 3D model of the tissues to be operated.

Since 2005, researchers have been working on bioprinting, that is, 3D printing 
of tissue with an ink made of cells and no longer synthetic materials. Impressions of skin and corneal fragments are already possible and American researchers have made a human ear from cells printed on a biodegradable scaffold [53].

\subsection{D Print-Orthopedic Applications}

$3 \mathrm{D}$ printing can produce $3 \mathrm{D}$ supporting structures in a controllable way and has taken its first steps in areas such as tissue engineering and regenerative medicine, along with advances in cell printing and biocopying and the innovation of printing materials. However, there is still a long way to go to perform organ printing

An important benefit of 3D printing in the orthopedic field is for testing and planning purposes. The ability to test treatments or implants on exactly accurate models is important. 3D printing can potentially speed up the processes involved in developing new devices, improving coordination between engineers and medical professionals.

Orthopedic surgeons can use 3D printed models to better plan their surgery and even use it during surgery for guidance. Some surgeons even perform surgery on the 3D printed model beforehand so they are more ready for the actual procedure. 3D printing definitely has application for implants and devices.

Imagine a surgeon needing a specific instrument or a modified replacement joint and able to create it on the place. Orthopedics is one of the most promising medical fields in 3D printing compared to fields dealing with soft tissue and organs. Structural replacement knee or hip implants customized for each patient through 3D printing would be an incredible medical advance [53].

\subsection{Preoperative Planning}

3D printing technology can help to produce bone models that can be used in complex orthopedic cases. Scenarios like compound fractures with bone loss, especially after high-speed road accidents and bomb explosions, are easily managed by developing a prototype on the contralateral side and can be used as a guide during surgery. In cases where there is no normal side to the model, normal anatomy can be used to create models which, in turn, can help assemble the missing parts.

Another scenario is complex joint replacement, in which the surgeon can develop a $3 \mathrm{D}$ model, knowing the possible intraoperative obstacles and planning accordingly.

Overall, the innovative use of 3D-printed replicas of bone fractures can help physicians, surgeons and researchers who thoroughly test methods before surgery begins [53].

\subsubsection{Complex Trauma}

$3 \mathrm{D}$ printing is especially useful in cases of complex trauma.

3D printed models provide visual and tactile aid in conceptualizing complex fracture patterns. The model can be sterilized and revised intraoperatively as 
needed. Preoperative reviews of the $3 \mathrm{D}$ model can allow the surgeon to anticipate intraoperative difficulties, select the best approach and need for specific equipment. Challenging pelvic fractures provide an example of these concepts. [53]

\subsubsection{Arthroplasty}

Most implant companies have 3D printed guides available to assist with standard knee joint arthroplasty. This process is commonly called patient-specific instrumentation. Patients have a CT or MRI scan to produce DICOM images.

3D images are created and a preoperative surgical plan is constructed to achieve perfect implant placement. Disposable cutting blocks are then manufactured

Proposed benefits include better reproducibility of component alignment, reduced surgical time, and optimized efficiency and cost-effectiveness. Despite these proposed benefits, it has yet to be proven that it is better than standard techniques.

3D printing allowed for the emergence of personalized implants. Custom implants for joint arthroplasty are useful when the patient does not fit into the standard range of implant size or their disease [53].

\subsubsection{Spinal Surgery}

Preoperative computer-aided planning and personalized 3D printing.

\subsubsection{Pediatric Orthopedics}

Pediatric orthopedic surgeons used 3D-printed models to assist in the management of complex spinal scoliosis, foot coalition, and Perthes and Blount disease.

3D printing can produce templates to allow pre-drilling holes for custom plates with built-in osteotomy guides.

Using computed tomography (CT) and magnetic resonance imaging, 3D images of bones can be formulated and reconstructed by a $3 \mathrm{D}$ printer. The printed template can then be used for teaching, better understanding of the individual's problems, and surgical guidance. In cases of degeneration, the imprinted bones can be compared with other anatomical models and with the patient's other bones, so that the manufacture of implanted parts can be better oriented.

One of the main advantages of 3D printing on orthopedic implants is the geometric freedom inherent in the technology. This not only allows for the design of more natural anatomical shapes, but also offers the possibility to design porous bone replacement scaffolds that can be seamlessly integrated into the implant design. This allows for natural bone growth, ensuring greater implant stability.

Improvements in implant design are an important area that can be effectively addressed using $3 \mathrm{D}$ printing. Before, during normal manufacturing times, even small design changes took a lot of time, but with the advent of rapid prototyping technology, the designer can improvise and develop a new implant. It can be easily available and much cheaper than the old implant creation protocol. The 
developer can verify the prototype's accuracy and any fallacies and can quickly request changes and re-evaluate the resulting product. Certain metals like titanium have been approved to be used in these 3D printers and can help manufacture implants.

$3 \mathrm{D}$ printing technology is very promising in all fields of medicine, but the field that has been most revolutionized is the field of orthopedics. It has widespread implications for research, development and improvement of surgical outcomes.

Future studies may be carried out to assess the following:

- Study the utility and applicability of 3D printing for complex orthopedic applications problems;

- Evaluate the clinical-radiological results of these cases, using 3D printing;

- Determine the cost-effectiveness of 3D printing in these challenging cases;

- Evaluate the best indications for 3D printing in difficult orthopedic cases;

- Analyze the complexities associated with $3 \mathrm{D}$ printing and how to overcome these issues.

$3 \mathrm{D}$ printing is the perfect technology to support the ongoing evolution of personalized digital medicine, creating a digital segment that starts with the medical imaging process, over treatment planning, implant design, patient communication and ends with digital manufacturing of a custom implant and instrumentation [53].

\section{Conclusions}

Nanoskin ${ }^{\otimes}$ (Bacterial cellulose) review shows several applications of this wound healing membrane. Clinical cases with recent covid-19 and tumor wounds are details and future insights with $3 \mathrm{~d}$ print wound healing are discussed.

Our recent results in tumor wounds are a new and natural treatment for wound healing, without cancer drugs, chemotherapy or radiotherapy.

In conclusion, Nanoskin ${ }^{\circledast}$ (Bacterial cellulose membranes) applies for different wound healing treatments, since covid-19 until tumor wounds, besides this membrane can be produced by biotechnological process or $3 \mathrm{~d}$ print applications.

\section{Conflicts of Interest}

The authors declare no conflicts of interest regarding the publication of this paper.

\section{References}

[1] ASTM Standard E2456 (2006) Standard Terminology Relating to Nnaotechnology. ASTM International, West Conshohocken. https://doi.org/10.1520/E2456-06

[2] Buzea, C., Pacheco, I.I. and Robbie, K. (2007) Nanomaterials and Nanoparticles: Sources and Toxicity. Biointerphases, 2, MR17-MR71. https://doi.org/10.1116/1.2815690

[3] Mühling, M., Bradford, A., Readman, J.W., Somerfield, P.J. and Handy, R.D. (2009) An Investigation into the Effects of Silver Nanoparticles on Antibiotic Resistance of Naturally Occurring Bacteria in an Estuarine Sediment. Marine Environmental Re- 
search, 68, 278-283. https://doi.org/10.1016/j.marenvres.2009.07.001

[4] Drake, P.L. and Hazelwood, K.J. (2005) Exposure-Related Health Effects of Silver and Silver Compounds: A Review. Annals of Occupational Hygiene, 49, 575-585.

[5] White, J.M.L., Powell, A.M., Brady, K. and Russell-Jones, R. (2003) Severe Generalized Argryia Secondary Ingestion of Colloidal Silver Protein. Clinical and Experimental Dermatology, 28, 254-256. https://doi.org/10.1046/j.1365-2230.2003.01214.x

[6] Lee, H.J., Yeo, S.Y. and Jeong, S.H. (2003) Antibacterial Effect of Nanosized Silver Colloidal Solution on Textile Fabrics. Journal of Materials Science, 38, 2199-2204. https://doi.org/10.1023/A:1023736416361

[7] Lee, K.J., Lee, Y., Shim, I., Joung, J. and Oh, Y.S. (2006) Direct Synthesis and Bonding Origins of Monolayer-Protected Silver Nanocrystals from Silver Nitrate through in Situ Ligand Exchange. Journal of Colloid and Interface Science, 304, 92-97. https://doi.org/10.1016/j.jcis.2006.08.037

[8] Lee, K.J., Lee, Y., Shim, I., Jun, B.H., Cho, H.J. and Joung, J. (2007) Large-Scale Synthesis of Polymer-Stabilized Silver Nanoparticles. Solid State Phenomena, 124126, 1189-1192. https://doi.org/10.4028/www.scientific.net/SSP.124-126.1189

[9] Lee, K.J., Nallathamby, P.D., Browning, L.M., Osgood, C.J. and Xu, X.N. (2007) In Vivo Imaging of Transport and Biocompatibility of Single Silver Nanoparticles in Early Development of Zebrafish Embryos. Journal of the American Chemical Society, 1, 133-143. https://doi.org/10.1021/nn700048y

[10] Lee, K.J., Park, J.T., Goh, J.H. and Kim, J.H. (2008) Synthesis of Amphiphilic Graft Copolymer Brush and Its Use as Template Film for the Preparation of Silver Nanoparticles. Journal of Polymer Science Part A Polymer Chemistry, 46, 3911-3918. https://doi.org/10.1002/pola.22718

[11] Gatti, A.M. (2004) Biocompatibility of Micro- and Nano-Particles in the Colon. Part II. Biomaterials, 25, 385-392. https://doi.org/10.1016/S0142-9612(03)00537-4

[12] Gatti, A.M., Montanari, S., Monari, E., Gambarelli, A., Capitani, F. and Parisini, B. (2004) Detection of Micro- and Nano-Sized Biocompatible Particles in the Blood. Journal of Materials Science: Materials in Medicine, 15, 469-472. https://doi.org/10.1023/B:JMSM.0000021122.49966.6d

[13] Poon, V.K. and Burd, A. (2004) In Vitro Cytotoxity of Silver: Implication for Clinical Wound Care. Burns, 30, 140-147. https://doi.org/10.1016/j.burns.2003.09.030

[14] Asharani, P.V., Nair, G., Zhiyuan, H., Manoor, P. and Valiyaveettil, S. (2007) Potential Health Impacts of Silver Nanoparticles. Abstracts of Papers, 234th ACS National Meeting, Boston, 19-23 August 2007, TOXI-099.

[15] Braydich-Stolle, L., Hussain, S., Schlager, J.J. and Hofmann, M.C. (2005) In Vitro Cytotoxicity of Nanoparticles in Mammalian Germline Stem Cells. Toxicological Sciences, 88, 412-419. https://doi.org/10.1093/toxsci/kfi256

[16] Olyveira, G.M., Costa, L.M.M., Riccardi, C.S., Santos, M.L., Daltro, P.B., Basmaji, P., Daltro, G.C. and Guastaldi, A.C. (2016) Bacterial Cellulose for Advanced Medical Materials. In: Grumezescu, A.M., Ed., Nanobiomaterials in Soft Tissue Engineering, Elsevier, Romania, 57-82. https://doi.org/10.1016/B978-0-323-42865-1.00003-9

[17] Olyveira, G.M., Santos, M.L., Costa, L.M.M., Daltro, P.B., Basmaji, P., Daltro, G.C. and Guastaldi, A.C. (2014) Bacterial Biocomposites for Guided Tissue Regeneration. Science of Advanced Materials, 6, 2673-2678. https://doi.org/10.1166/sam.2014.1985

[18] Olyveira, G.M., Santos, M.L., Costa, L.M.M., Daltro, P.B., Basmaji, P., Daltro, G.C. and Guastaldi, A.C. (2015) Physically Modified Bacterial Cellulose Biocomposites 
for Guided Tissue Regeneration. Science of Advanced Materials, 7, 1657-1664. https://doi.org/10.1166/sam.2015.2283

[19] Olyveira, G.M., Basmaji, P., Costa, L.M.M., Santos, M.L., Riccardi, C.S., Guastaldi, F.P.S., Scarel-Caminaga, R.M., Oliveira Capote, T.S., Pizoni, E. and Guastaldi, A.C. (2017) Surface Physical Chemistry Properties in Coated Bacterial Cellulose Membranes with Calcium Phosphate. Materials Science \& Engineering. C, Materials for Biological Applications, 75, 1359-1365. https://doi.org/10.1016/j.msec.2017.03.025

[20] Al Mualla, S., Al Nabooda, M., Salman, N., Basmaji, P., De Olyveira, G., Manzine Costa, L., Da Costa Oliveira, J. and Francozo, G. (2018) Special Nanoskin-ACT-Biological Membranes from Deep Wounds. Journal of Biomaterials and Nanobiotechnology, 9, 79-88. https://doi.org/10.4236/jbnb.2018.91007

[21] M. Kanjou, M., Abdulhakim, H., Olyveira, G. and Basmaji, P. (2019) 3-D Print Celulose Nanoskin: Future Diabetic Wound Healing. Journal of Biomaterials and Nanobiotechnology, 10, 190-195. https://doi.org/10.4236/jbnb.2019.104011

[22] Basmaji, P. (2020) First Breast Cancer Treatment Naturally by Nanoskin Act. Journal of Biomaterials and Nanobiotechnology, 11, 179-187.

https://doi.org/10.4236/jbnb.2020.113011

[23] El-Hoseny, S., Basmaji, P., Olyveira, G., Costa, L., Alwahedi, A., Oliveira, J. and Francozo, G. (2015) Natural ECM-Bacterial Cellulose Wound Healing-Dubai Study. Journal of Biomaterials and Nanobiotechnology, 6, 237-246. https://doi.org/10.4236/jbnb.2015.64022

[24] Mualla, S., Farahat, R., Basmaji, P., Olyveira, G., Costa, L., Oliveira, J. and Francozo, G. (2016) Study of Nanoskin ECM-Bacterial Cellulose Wound Healing/United Arab Emirates. Journal of Biomaterials and Nanobiotechnology, 7, 109-117. https://doi.org/10.4236/jbnb.2016.72012

[25] Basmaji, P., Molina de Olyveira, G. and Kanjou, M. (2021) Skin Cancer Treatment by Nanoskin Cellulose: Future Cancer Wound Healing. Journal of Biomaterials and Nanobiotechnology, 12, 1-6. https://doi.org/10.4236/jbnb.2021.121001

[26] Basmaji, P., Martins, V. and Kanjo, M. (2020) Natural Nanoskin ACT Management of the Rare Disease as Burnt Patient with Epidermolysis Bullosa and Stevens-Johnson. Journal of Biomaterials and Nanobiotechnology, 11, 188-194. https://doi.org/10.4236/jbnb.2020.113012

[27] Viveiros, M.M.H., Rainho, C.A., Ramirez, J.A.Z., Kaneno, R., Silva, M.G., Ximenes, V.F., de Olyveira, G.M., Basmaji, P., Di Girolamo, N. and Schellini, S.A. (2022) Physical, Functional and Biochemical Features of Nanoskin ${ }^{\circledR}$ Bacterial Cellulose Scaffold as a Potential Carrier for Cell Transference. Materials Letters Part A, 308, Article ID: 131109. https://doi.org/10.1016/j.matlet.2021.131109

[28] Ji, J.H., Jung, J.H., Kim, S.S., Yoon, J.U., Park, J.D., Choi, B.S., Chung, Y.H., Kwon, I.H., Jeong, J., Han, B.S., Shin, J.H., Sung, J.H., Song, K.S., Yu, I.J. (2007) Twenty-Eight-Day Inhalation Toxicity Study of Silver Nanoparticles in Sprague-Dawley Rats. Inhalation Toxicology, 19, 857-871. https://doi.org/10.1080/08958370701432108

[29] El-Ansary, A. and Al-Daihan, S. (2009) On the Toxicity of Therapeutically Used Nanoparticles: An Overview. Journal of Toxicology, 2009, Article ID: 754810. https://doi.org/10.1155/2009/754810

[30] Oberdörster, G., Oberdörster, E. and Oberdörster, J. (2005) Nanotoxicology: An Emerging Discipline Evolving from Studies of Ultrafine Particles. Environmental Health Perspectives, 113, 823-839. https://doi.org/10.1289/ehp.7339

[31] Oberdörster, G., Maynard, A., Donaldson, K., Castranova, V., Fitzpatrick, J., Ausman, 
K., Carter, J., Karn, B., Kreyling, W., Lai, D., Olin, S., Monteiro-Riviere, N., Warheit, D. and Yang, H. (2005) Principles for Characterizing the Potential Human Health Effects from Exposure to Nanomaterials: Elements of a Screening Strategy. Particle and Fibre Toxicology, 2, 8-43. https://doi.org/10.1186/1743-8977-2-8

[32] Oberdörster, G., Stone, V. and Donaldson, K. (2007) Toxicology of Nanoparticles: A Historical Perspective. Nanotoxicology, 1, 2-25. https://doi.org/10.1080/17435390701314761

[33] Hagens, W.I., Oomen, A.G., de Jong, W.H., Cassee, F.R. and Sips, A.J.A.M. (2007) What Do We (Need to) Know about the Kinetic Properties of Nanoparticles in the Body? Regulatory Toxicology and Pharmacology, 49, 217-229. https://doi.org/10.1016/j.yrtph.2007.07.006

[34] Moghimi, S.M., Hunter, A.C. and Murray, J.C. (2005) Nanomedicine: Current Status and Future Prospects. FASEB Journal, 19, 311-330.

https://doi.org/10.1096/fj.04-2747rev

[35] Trop, M., Novak, M., Rodl, S., Hellbom, B., Kroell, W. and Goessler, W. (2006) Silver-Coated Dressing Acticoat Caused Raised Liver Enzymes and Argyria-Like Symptoms in Burn Patient. The Journal of Trauma, 60, 648-652.

https://doi.org/10.1097/01.ta.0000208126.22089.b6

[36] Dockery, D.W., Luttmann-Gibson, H., Rich, D.Q., Link, M.S., Mittleman, M.A., Gold, D.R., Koutrakis, P., Schwartz, J.D. and Verrier, R.L. (2005) Association of Air Pollution with Increased Incidence of Ventricular Tachyarrhythmias Recorded by Implanted Cardioverter Defibrillators. Environmental Health Perspectives, 113, 670674. https://doi.org/10.1289/ehp.7767

[37] Donaldson, K., Stone, V., Tran, C., Kreyling, W. and Borm, P.J.A. (2004) Nanotoxicology. Occupational and Environmental Medicine, 61, 727-728. https://doi.org/10.1136/oem.2004.013243

[38] Shah, C.P. (2007) Public Health and Preventive Medicine in Canada. University of Toronto Press, Toronto.

[39] Vermylen, J., Nemmar, A., Nemery, B. and Hoylaerts, F. (2005) Ambient Air Pollution and Acute Myocardial Infarction. Journal of Thrombosis and Haemostasis, 3 , 1955-1961. https://doi.org/10.1111/j.1538-7836.2005.01471.x

[40] Peters, A. (2005) Particulate Matter and Heart Disease: Evidence from Epidemiological Studies. Toxicology and Applied Pharmacology, 207, S477-S482. https://doi.org/10.1016/j.taap.2005.04.030

[41] Chen, H.W., Su, S.F., Chien, C.T., Lin, W.H., Yu, S.L., Chou, C.C., Chen, J.J. and Yang, P.C. (2006) Titanium Dioxide Nanoparticles Induce Emphysema-Like Lung Injury in Mice. The FASEB Journal, 20, 2393-2395.

https://doi.org/10.1096/fj.06-6485fje

[42] Chen, J., Tan, M., Nemmar, A., Song, W., Dong, M., Zhang, G. and Li, Y. (2006) Quantification of Extrapulmonary Translocation of Intratracheal-Instilled Particles in Vivo in Rats: Effect of Lipopolysaccharide. Toxicology, 222, 195-201. https://doi.org/10.1016/j.tox.2006.02.016

[43] Supp, A.P., Neely, A.N., Supp, D.M., Warden, G.D. and Boyce, S.T. (2005) Evaluation of Cytotoxicity and Antimicrobial Activity of Acticoat ${ }^{\circledR}$ Burn Dressing for Management of Microbial Contamination in Cultured Skin Substitutes Grafted to Athymic Mice. Journal of Burn Care \& Rehabilitation, 26, 238-246.

[44] Wright, J.B., Lam, K., Buret, A.G., Olson, M.E. and Burrell, R.E. (2002) Early Healing Events in a Porcine Model Contaminated Wounds: Effects of Nanocrystalline Silver on Matrix Metalloproteinases, Cell Apoptosis, and Healing. Wound Repair 
and Regeneration, 10, 141-151. https://doi.org/10.1046/j.1524-475X.2002.10308.x

[45] Paddle-Ledinek, J.E., Nasa, Z. and Cleland, H.J. (2006) Effect of Different Wound Dressings on Cell Viability and Proliferation. Plastic and Reconstructive Surgery, 117, 110S-118S. https://doi.org/10.1097/01.prs.0000225439.39352.ce

[46] Wijnhoven, S.W.P., Peijnenburg, W.J.G.M., Herberts, C.A., Hagens, W.I., Oomen, A.G., Heugens, E.H.W., Roszek, B., Bisschops, J., Gosens, I., van de Meent, D., Dekkers, S., de Jong, W.H., van Zijverden, M., Sips, A.J.A.M. and Geertsma, R.E. (2009) Nanosilver-A Review of Available Data and Knowledge Gaps in Human and Environmental Risk Assessment. Nanotoxicology, 3, 109-138.

https://doi.org/10.1080/17435390902725914

[47] Kim, W.-Y., Kim, J., Park, J.D., Ryu, H.Y. and Yu, I.J. (2009) Histological Study of Gender Differences in Accumulation of Silver Nanoparticles in Kidneys of Fischer 344 Rats. Journal of Toxicology and Environmental Health, Part A, 72, 1279-1284. https://doi.org/10.1080/15287390903212287

[48] Kim, Y.S., Kim, J.S., Cho, H.S., Rha, D.S., Kim, J.M., Park, J.D., Choi, B.S., Lim, R., Chang, H.K., Chung, Y.H., Kwon, I.H., Jeong, J., Han, B.S. and Yu, I.J. (2008) Twenty-Eight-Day Oral Toxicity, Genotoxicity, and Gender-Related Tissue Distribution of Silver Nanoparticles in Sprague-Dawley Rats. Inhalation Toxicology, 20, 575-583. https://doi.org/10.1080/08958370701874663

[49] Holt, K.B. and Bard, A.J. (2005) Interaction of Silver (I) Ions with the Respiratory Chain of Escherichia coli: An Electrochemical and Scanning Electrochemical Microscopy Study of the Antimicrobial Mechanism of Micromolar Ag+. Biochemistry, 44, 13214-13223. https://doi.org/10.1021/bi0508542

[50] Muangman, P., Chuntrasakul, C., Silthram, S., Suvanchote, S., Benjathanung, R., Kittidacha, S. and Rueksomtawin, S. (2006) Comparison of Efficacy of 1\% Silver Sulfadiazine and Acticoat ${ }^{\mathrm{Tm}}$ for Treatment of Partial-Thickness Burn Wounds. Journal of the Medical Association of Thailand, 89, 953-958.

[51] Lok, C.-N., Ho, C.-M., Chen, R., He, Q.-Y., Yu, W.-Y., Sun, H., Tam, P.K.-H., Chiu, J.-F. and Che, C.-M. (2006) Proteomic Analysis of the Mode of Antibacterial Action of Silver Nanoparticles. Journal of Proteome Research, 5, 916-924. https://doi.org/10.1021/pr0504079

[52] Zeiri, I., Bronk, B.V., Shabtai, Y., Eichler, J. and Efrima, S. (2004) Surface Enhanced Raman Spectroscopy as a Tool for Probing Specific Biochemical Components in Bacteria. Applied Spectroscopy, 58, 33-40.

https://doi.org/10.1366/000370204322729441

[53] Kaminagakura, K.L.N., Sue Sato, S., Sugino, P., Kataki de Oliveira Veloso, L., dos Santos, D.C., Padovani, C.R., Basmaji, P., Olyveira, G. and Schellini, S.A. (2018) Nanoskin $^{\circledast}$ to Treat Full Thickness Skin Wounds. Journal of Biomedical Materials Research Part B-Applied Biomaterials, 107, 724-732.

https://doi.org/10.1002/jbm.b.34166 